\title{
Flora arbustivo-arbórea do Parque Estadual do Jaraguá, São Paulo - SP
}

\author{
Flaviana Maluf de Souza ${ }^{1,3}$, Rita de Cássia Sousa ${ }^{2}$, \\ Rejane Esteves $^{1}$ \& Geraldo Antônio Daher Corrêa Franco ${ }^{1}$ \\ ${ }^{1}$ Seção de Ecologia Florestal, Instituto Florestal de São Paulo, \\ Rua do Horto, 931, CEP 02377-000, São Paulo, SP, Brasil, www.iflorestal.sp.gov.br \\ ${ }^{2}$ Graduação em Ciências Biológicas, Universidade Nove de Julho, \\ Rua Dr. Adolfo Pinto, 109, CEP 01156-050, Barra Funda, São Paulo, SP, Brasil \\ ${ }^{3}$ Autor para correspondência: Flaviana Maluf de Souza, e-mail: flavianams@yahoo.com.br
}

SOUZA, F.M., SOUSA, R.C., ESTEVES, R., FRANCO, GADC. Floristic composition of tree and shrub species of the Jaraguá State Park, São Paulo - SP, Brazil. Biota Neotrop., 9(2): http://www.biotaneotropica. org.br/v9n2/en/abstract?iventory+bn00909022009.

\begin{abstract}
The objective of this study was to characterize the floristic composition of trees and shrubs of the Jaraguá State Park (PEJ), contributing to the knowledge of its biodiversity. Reproductive botanic material was collected along three trails during a 12-month period. The field survey resulted in a flora of 262 native species, 153 genera and 55 families. Fabaceae was the richest family (30 species), followed by Myrtaceae (26), Asteraceae (24), Melastomataceae (20), Lauraceae (16) and Rubiaceae (15). As mentioned for other forest remnants in São Paulo metropolitan region and surroundings, the PEJ vegetation is in a transition zone, where the main formation is the ombrophilous dense forest, but where species of seasonal semi-deciduous forest also occur. Besides that, there is a completely different phytophysiognomy occurring in a region with rocky outcrops and low depth soils, in which cerrado species were found, and that deserves more specific studies. In this site, the vegetation of grasses is the most abundant, and there are also shrubs and trees sparsely distributed, many of them with low height and suberous trunk. Most specifically in this area there were 55 species of 41 genera and 18 families, from which 22 did not occur in the other sites visited. Asteraceae was the family with the higher number of species (15), followed by Myrtaceae (7), Fabaceae (5) and Melastomataceae (4). Twenty exotic species were found along the trails. Despite the fact that PEJ has a big area of secondary vegetation and that it is exposed to strong anthropogenic pressures, there were 14 species belonging to some threat category defined at the official red lists, reinforcing the importance of the Park for biodiversity conservation.

Keywords: tropical rainforest, ombrophilous dense forest, seasonal semi-deciduous forest, savanna, highland grassland.
\end{abstract}

SOUZA, F.M., SOUSA, R.C., ESTEVES, R., FRANCO, GADC. Flora arbustivo-arbórea do Parque Estadual do Jaraguá, São Paulo - SP. Biota Neotrop., 9(2): http://www.biotaneotropica.org.br/v9n2/pt/abstract?iventory+ bn00909022009.

Resumo: O objetivo deste trabalho foi caracterizar a flora arbustivo-arbórea do Parque Estadual do Jaraguá (PEJ), a fim de contribuir para o conhecimento de sua diversidade. Foram feitas coletas mensais de material reprodutivo dos indivíduos arbustivos e arbóreos ao longo de três trilhas, durante um período de 12 meses. O levantamento resultou em uma lista florística contendo 262 espécies nativas, de 153 gêneros e 55 famílias. As famílias mais representativas foram Fabaceae, com 30 espécies, Myrtaceae (26), Asteraceae (24), Melastomataceae (20), Lauraceae (16) e Rubiaceae (15). Assim como relatado para outros remanescentes da região metropolitana de São Paulo e entorno, a vegetação do PEJ está situada em uma zona de transição, onde predomina a floresta ombrófila densa, com a presença de algumas espécies de floresta estacional semidecidual. Destaca-se ainda a existência de uma outra fitofisionomia em uma região de afloramentos de rocha e solo raso, onde ocorrem espécies de cerrado, e que merece estudos específicos. Nessa área, a vegetação é predominantemente herbácea, com árvores e arbustos esparsos, em geral de pequeno porte e com tronco suberoso. Especificamente nessa formação, foram registradas 55 espécies pertencentes a 41 gêneros e 18 famílias, das quais 22 não ocorreram nos outros locais amostrados. A família com maior riqueza foi Asteraceae (15 espécies), seguida por Myrtaceae (7), Fabaceae (5) e Melastomataceae (4). Em todo o levantamento, foram contabilizadas 20 espécies exóticas. Apesar de grande parte da vegetação do Parque ser secundária e estar exposta a fortes pressões antrópicas, foram encontradas 14 espécies presentes em alguma das categorias existentes nas listas oficiais de espécies ameaçadas, reforçando a importância do PEJ para a conservação da biodiversidade.

Palavras-chave: florística, floresta ombró la densa, floresta estacional semidecidual, cerrado, campo de altitude. 


\section{Introdução}

A progressiva redução da cobertura vegetal nativa do estado de São Paulo, decorrente sobretudo da intensa exploração madeireira, da expansão agropecuária e do crescimento industrial e urbano, atingiu toda a vegetação do estado, desde as formações litorâneas até as áreas de cerrado e de floresta estacional (Victor 1975, Dean 1996, Kronka et al. 2005). Os remanescentes de maior extensão localizam-se ao longo da Serra do Mar, a leste do estado, onde a topografia acidentada inviabilizou o uso da terra para outras finalidades.

A região metropolitana de São Paulo é um inevitável centro de pressões urbanas e, com isso, as poucas áreas de vegetação remanescentes tendem a ser cada vez mais reduzidas. Entre 2005 e 2008, o desmatamento nessa região aumentou consideravelmente em relação ao período compreendido pelos cinco anos anteriores, em uma ordem de grandeza de 10 vezes (SOS Mata Atlântica 2008). Nesse cenário de pressões e perturbações constantes, os remanescentes que se encontram protegidos nas Unidades de Conservação, como os Parques Estaduais Alberto Löfgren, Cantareira, Fontes do Ipiranga, Jaraguá, Juquery e alguns núcleos do Parque Estadual da Serra do Mar, constituem importantes refúgios para espécies animais e vegetais e o conhecimento sobre sua biodiversidade é fundamental para estabelecer estratégias de conservação das espécies e restauração dos ecossistemas.

Embora o Parque Estadual do Jaraguá (PEJ) esteja localizado na cidade de São Paulo e seja de fácil acesso, sua vegetação é praticamente desconhecida. As informações mais antigas constam em relatos de A. Usteri (1908), um pesquisador alemão que estudou a flora da região metropolitana de São Paulo. Contudo, não existem estudos detalhados sobre a vegetação do PEJ e as únicas informações sobre sua flora provêm de coletas isoladas, que se encontram dispersas em algumas coleções biológicas do país.

O conhecimento da composição florística é um importante instrumento para subsidiar projetos de pesquisa em diversas áreas do conhecimento, bem como para auxiliar no processo de elaboração do plano de manejo e do zoneamento de uma Unidade de Conservação. Especialmente no caso do PEJ, a localização em uma região de transição entre áreas de floresta ombrófila densa, floresta estacional e cerrado (Kronka et al. 2005) reforça a necessidade do conhecimento de sua flora para que se possa identificar as diferentes fitofisionomias dentro do mosaico vegetacional e avaliar o grau de conservação da vegetação. Assim, o objetivo deste trabalho foi caracterizar a flora arbustivo-arbórea do Parque Estadual do Jaraguá, contribuindo para o conhecimento de sua diversidade e fornecendo informações para auxiliar na definição de propostas de pesquisa, conservação e manejo.

\section{Materiais e Métodos}

\section{1. Área de estudo}

Este trabalho foi realizado no Parque Estadual do Jaraguá (PEJ), que se localiza na região Noroeste do município de São Paulo $\left(23^{\circ} 27^{\prime} 42^{\prime \prime} \mathrm{S}\right.$ e $46^{\circ} 45^{\prime} 44^{\prime}$ 'W) e abrange uma área de 492,68 ha (Instituto Florestal 2007), em altitudes variando de 735 a 1.125 m (Figura 1). O clima da região é classificado como Cfb (Köppen 1948), ou seja, temperado de inverno seco, com temperatura média do mês mais quente inferior a $22{ }^{\circ} \mathrm{C}$ e do mês mais frio, inferior a $18{ }^{\circ} \mathrm{C}$ (Ventura et al. 1965/1966); a precipitação média anual é de 1.500 a $1.600 \mathrm{~mm}$ (Roque et al. 2003).

Na região, predomina o Argissolo Vermelho-Amarelo Distrófico de textura argilosa, em relevo forte ondulado e montanhoso, associado ao Cambissolo Háplico Distrófico de textura argilosa, em relevo montanhoso e escarpado (Oliveira et al. 1999).
De acordo com o mapeamento do Inventário Florestal de São Paulo (Kronka et al. 2005), a vegetação do Parque é definida como floresta ombrófila densa montana (sensu Veloso et al. 1991). Contudo, o PEJ possui também um trecho de vegetação composto predominantemente por espécies herbáceas, com algumas árvores e arbustos esparsos e que não se enquadra nessa classificação (Figura 2). A ausência dessa vegetação no Inventário decorre provavelmente da pequena área ocupada por esse trecho em relação à escala utilizada. Para distingui-la dos trechos com fisionomia tipicamente florestal característicos do Parque, essa área será tratada ao longo do texto como "campo", apenas pela semelhança fisionômica, mas sem conotação de similaridade florística com os campos naturais. Diante da inexistência de informações espacializadas desse tipo vegetacional no PEJ, optou-se por apresentar uma delimitação preliminar dessa área, a fim de possibilitar uma melhor visualização da extensão e localização dessa formação na paisagem (Figura 1).

O PEJ é margeado por duas grandes rodovias (Rodovia dos Bandeirantes e Rodovia Anhangüera) e tem uma intensa atividade de visitação, recebendo cerca de 360.000 pessoas por ano. Essa situação torna o Parque bastante vulnerável às pressões antrópicas e exposto a constantes perturbações. Dentre os fatores de maior impacto sobre a conservação da flora e da fauna do PEJ estão os incêndios, que ocorrem especialmente na parte mais alta, onde predomina a vegetação de gramíneas (V. A. Almeida, comunicação pessoal).

O Parque conta com quatro trilhas oficiais destinadas à visitação pública (Trilha da Bica, Trilha do Lago, Trilha do Pai Zé e Trilha do Silêncio) e algumas trilhas secundárias, utilizadas pela equipe de segurança para a fiscalização.

\section{Levantamento florístico}

Após algumas visitas de reconhecimento, foram selecionadas as trilhas para a realização do levantamento florístico. A definição das trilhas foi feita considerando o estádio de conservação da vegetação, a acessibilidade e a possibilidade de percorrer o gradiente altitudinal do Parque, a fim de amostrar diferenças florísticas eventualmente existentes e possivelmente associadas a ele. De acordo com esses critérios, selecionou-se uma trilha de uso público (Trilha do Pai Zé) e duas trilhas utilizadas para a fiscalização (Trilha do Mauro e Trilha das Garças).

A trilha do Pai Zé possui extensão de $1.830 \mathrm{~m}$ e inicia-se na parte alta do Parque, a $1.080 \mathrm{~m}$ de altitude, terminando na área próxima ao portão de entrada principal, a aproximadamente $790 \mathrm{~m}$ de altitude. A trilha do Mauro estende-se por cerca de $1.490 \mathrm{~m}$ e abrange altitudes de 850 a $1.020 \mathrm{~m}$. A trilha das Garças, com $1.440 \mathrm{~m}$ de comprimento é a trilha que compreende a menor amplitude altitudinal, iniciando-se aproximadamente aos 760 e terminando aos $810 \mathrm{~m}$.

Para a caracterização da composição florística foram realizadas visitas mensais a todas as trilhas, durante 12 meses. A sistemática de coleta envolveu caminhadas ao longo das trilhas e eventuais deslocamentos para o interior, tendo sido coletadas amostras dos indivíduos arbustivos e arbóreos em estágio reprodutivo. Também foram registradas as espécies observadas ou coletadas sem material fértil, ou ainda aquelas que, embora em estágio reprodutivo, não puderam ser coletadas mesmo com auxílio de um escalador e cujo material reprodutivo (especialmente frutos), muitas vezes, foi observado no chão. Em todos esses casos, só foram incluídas na lista florística as espécies cuja identificação pôde ser feita com absoluta segurança. A coleta e herborização de material botânico foram realizadas de acordo com Fidalgo \& Bononi (1984).

Além das espécies nativas, registrou-se também a ocorrência de espécies exóticas ao longo das trilhas. Foram consideradas como espécies exóticas aquelas de ocorrência fora dos limites geográficos historicamente reconhecidos (Ziller 2001). 

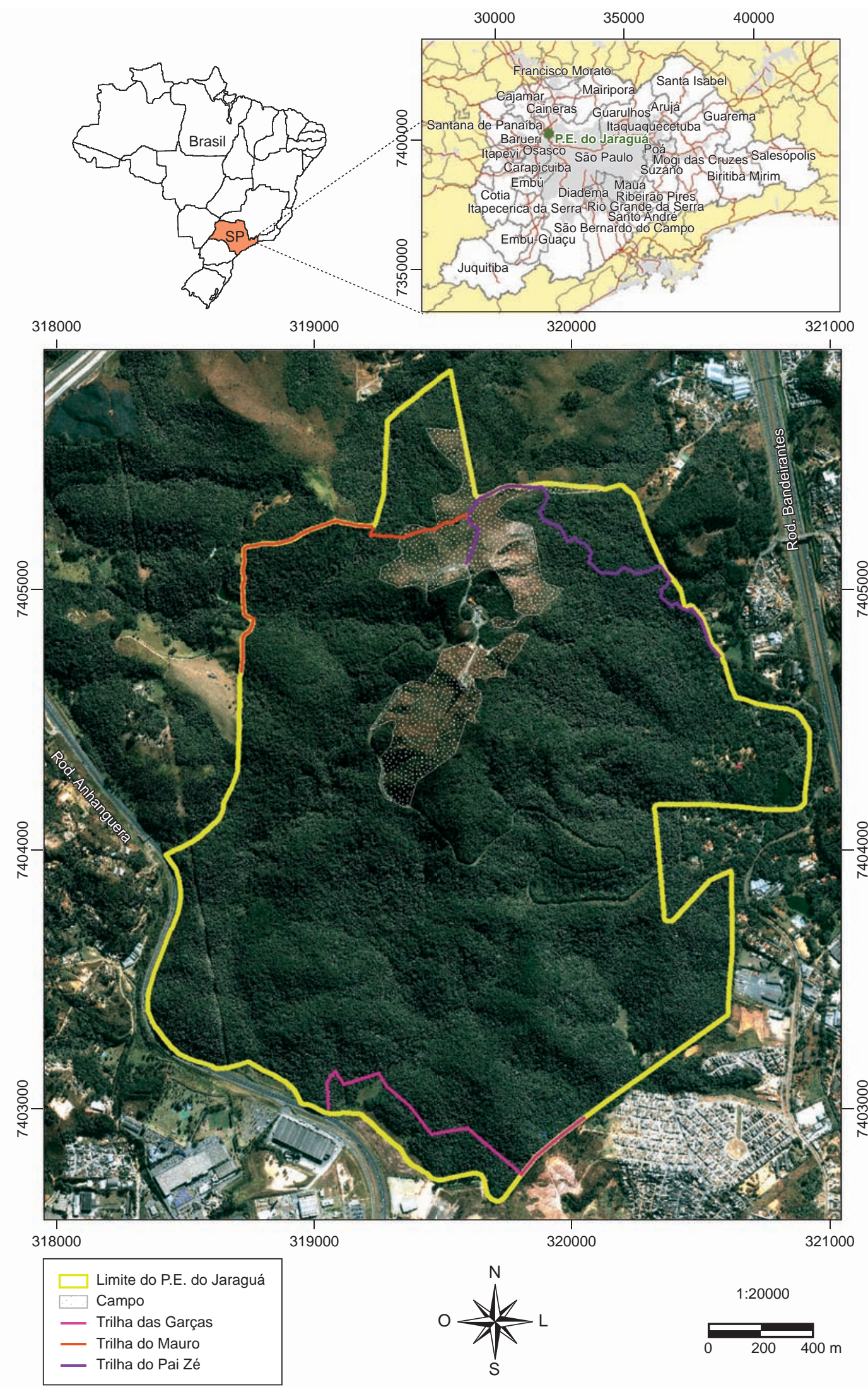

Figura 1. Localização do Parque Estadual do Jaraguá (São Paulo - SP) e mapa com as trilhas percorridas para o levantamento florístico. Fonte: Mattos \& Kanashiro (dados não publicados).

Figure 1. Location of the Jaraguá State Park (São Paulo - SP) and the map showing the trails selected for the floristic survey. Source: Mattos \& Kanashiro (unpublished data). 

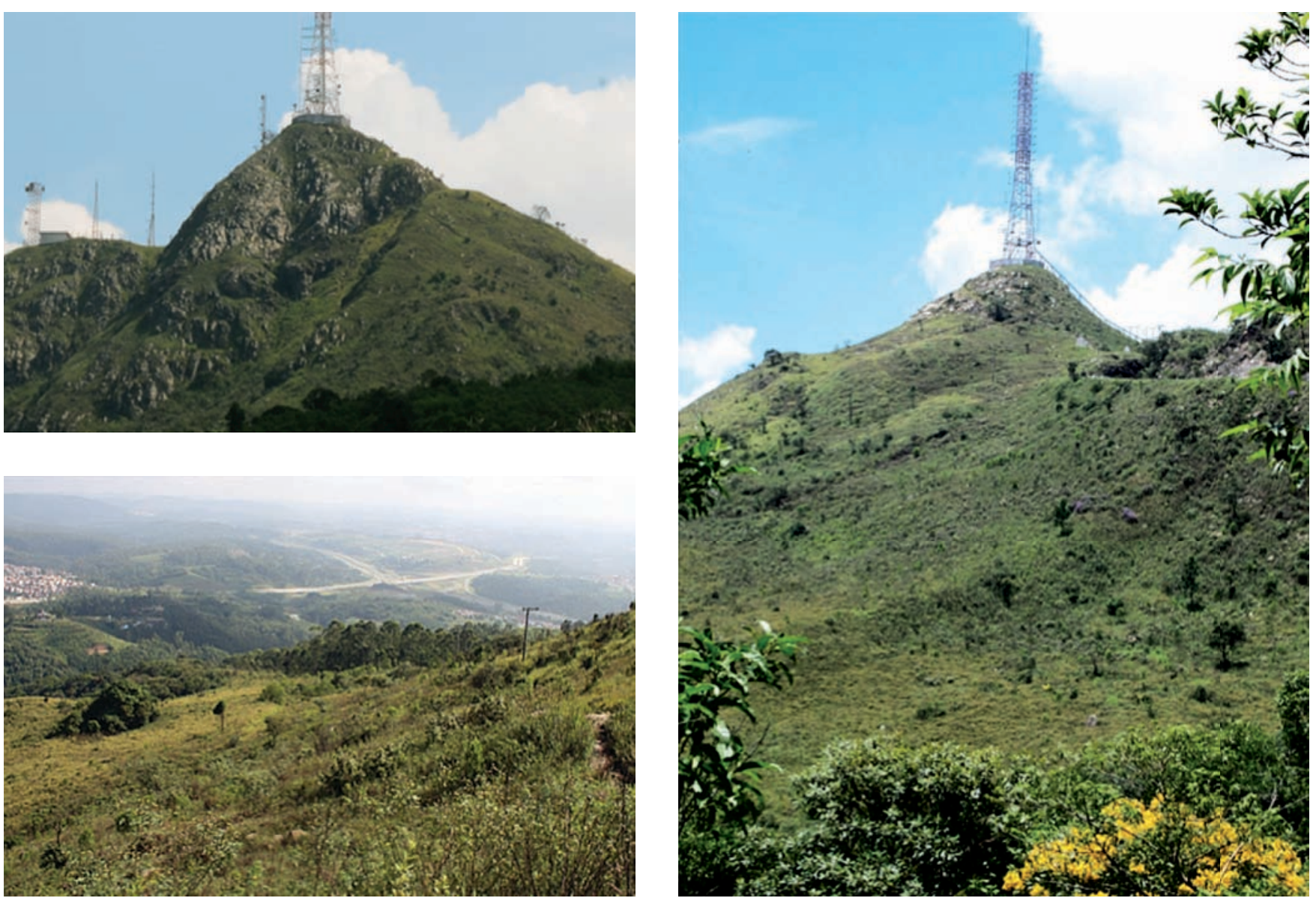

Figura 2. Aspectos da vegetação de "campo" e dos afloramentos de rocha no Parque Estadual do Jaraguá, São Paulo - SP.

Figure 2. Aspects of the "campo" vegetation and the rocky outcrops of the Jaraguá State Park, São Paulo - SP, Brazil.

O material coletado foi identificado por comparação com exsicatas presentes no acervo do herbário do Instituto Florestal de São Paulo (Herbário D. Bento Pickel - SPSF), além de consultas a bibliografia especializada e envio de material a especialistas. Os melhores exemplares coletados de cada espécie foram selecionados como material testemunho e depositados no herbário SPSF. Os detalhes de cada espécime podem ser consultados no Species Link (www.splink.cria.org.br). Duplicatas de alguns materiais foram enviadas aos herbários da UNICAMP (UEC - Asteraceae e Melastomataceae), ESALQ (ESA - Piperaceae) e UFMG (BHCB Solanaceae). A nomenclatura científica seguiu as normas propostas pelo APG II (Angiosperm Phylogeny Group II), com o auxílio de bibliografia (Souza \& Lorenzi 2007). A grafia e sinonimização das espécies foram verificadas utilizando os bancos de dados W3 Tropicos (MOBOT 2008), Royal Botanic Gardens (2008) e International Plant Names Index (IPNI 2008), ou ainda, indicadas pelos respectivos especialistas.

A lista de espécies oriunda do levantamento foi comparada com as listas oficiais de espécies ameaçadas de extinção no estado de São Paulo (Mamede et al. 2007), no Brasil (Biodiversitas 2008) e no mundo (IUCN 2006).

\section{Resultados e Discussão}

No levantamento de campo foram registradas 262 espécies arbustivas e arbóreas nativas, pertencentes a 153 gêneros de 55 famílias, sendo 169 espécies na trilha do Pai Zé, 162 espécies na trilha do Mauro e 107 espécies na trilha das Garças (Tabela 1). As famílias mais representativas foram Fabaceae (30 espécies), Myrtaceae (26), Asteraceae (24), Melastomataceae (20), Lauraceae (16) e Rubiaceae (15). Com exceção de Asteraceae, essas são as famílias mais frequientemente relatadas como as de maior riqueza em trabalhos publicados realizados em outros remanescentes da região do município de São Paulo e seu entorno, como a Serra do Japi, em Jundiaí (Leitão-Filho 1992), o fragmento estudado por Gandolfi et al. (1995) em Guarulhos, a Reserva da Cidade Universitária Armando de Salles Oliveira - USP (Dislich et al. 2001) e o Parque Santo Dias (Garcia \& Pirani 2001), localizados na própria capital, a Reserva Florestal do Morro Grande (Catharino et al. 2006) e o Parque CEMUCAM (Ogata \& Gomes 2006), no município de Cotia, os nove fragmentos estudados por Franco et al. (2007) em Embu, e os 21 remanescentes florestais localizados no município de Ibiúna (Bernacci et al. 2006).

A análise da composição florística indicou que a vegetação do PEJ é predominantemente característica da floresta ombrófila densa, com a presença de algumas espécies típicas de floresta estacional semidecidual, como Albizia polycephala (Benth.) Killip, Centrolobium tomentosum Guillemin ex Benth., Eugenia uniflora L. e Syagrus oleracea (Mart.) Becc. Pode-se dizer, portanto, que a vegetação do PEJ segue o padrão descrito para as florestas da região metropolitana de São Paulo e seu entorno, onde a flora tem um caráter de transição entre essas duas formações. Ressalta-se que a composição de espécies da floresta ombrófila e da floresta estacional semidecidual é geralmente influenciada pela altitude e pelas características climáticas associadas a ela, e a transição entre essas formações pode ocorrer de forma gradual e complexa (Oliveira-Filho \& Fontes 2000), dificultando muitas vezes a categorização fitogeográfica das manchas. 
Tabela 1. Espécies arbustivas e arbóreas registradas no Parque Estadual do Jaraguá, São Paulo - SP (Ga - trilha das Garças; Ma - trilha do Mauro; PZ - trilha do Pai Zé), com seu respectivo número de tombo no Herbário do Instituto Florestal de São Paulo (SPSF). (X) Presença; ( ) Ausência. Letras sobrescritas após o nome científico indicam a ocorrência (c) ou a ocorrência exclusiva (*) da espécie na área de "campo".

Table 1. Tree and shrub species of the Jaraguá State Park, São Paulo - SP (Ga - Garças trail; Ma - Mauro trail; PZ - Pai Zé trail), and the record number of voucher specimens at the Forest Institute Herbarium (SPSF). (X) Presence; ( ) Absence. Superscript letters after the scientific name mean that the species occurred (c) or were found exclusively (*) at the "campo" sites.

\begin{tabular}{|c|c|c|c|c|c|}
\hline \multirow[t]{2}{*}{ Família } & \multirow[t]{2}{*}{ Espécie } & \multirow[t]{2}{*}{ SPSF } & \multicolumn{3}{|c|}{ Trilha } \\
\hline & & & Ga & Ma & $\mathbf{P Z}$ \\
\hline \multicolumn{6}{|c|}{ Anacardiaceae } \\
\hline & Lithraea molleoides (Vell.) Engl. ${ }^{\mathrm{c}}$ & 39150 & & & $\mathrm{X}$ \\
\hline & Schinus terebinthifolius Raddi ${ }^{\mathrm{C}}$ & $39148 ; 39149$ & $\mathrm{X}$ & $\mathrm{X}$ & $\mathrm{X}$ \\
\hline & Tapirira obtusa (Benth.) J. D. Mitch ${ }^{\mathrm{C}}$ & & $\mathrm{X}$ & & $\mathrm{X}$ \\
\hline \multicolumn{6}{|c|}{ Annonaceae } \\
\hline & Annona cacans Warm. & $39146 ; 39147$ & $X$ & $X$ & $\mathrm{X}$ \\
\hline & Guatteria australis A. St. - Hil. & $39145 ; 39996$ & $X$ & $X$ & \\
\hline & Porcelia macrocarpa (Warm.) R. E. Fr. & 39143 & & & $\mathrm{X}$ \\
\hline & Rollinia sericea (R. E. Fr.) R. E. Fr. & $39141 ; 39142$ & $\mathrm{X}$ & $\mathrm{X}$ & $\mathrm{X}$ \\
\hline & Rollinia sylvatica (A. St. - Hil) & & $\mathrm{X}$ & $\mathrm{X}$ & \\
\hline \multicolumn{6}{|c|}{ Apocynaceae } \\
\hline & Rauvol a sellowii Müll. Arg. & 39140 & & $\mathrm{X}$ & \\
\hline & Tabernaemontana hystrix Steud. & & & & $\mathrm{X}$ \\
\hline \multicolumn{6}{|l|}{ Araliaceae } \\
\hline & Schefflera angustissima (Marchal) Frodin & 39139 & & $\mathrm{X}$ & $\mathrm{X}$ \\
\hline \multicolumn{6}{|l|}{ Arecaceae } \\
\hline & Euterpe edulis Mart. & 39153 & & $\mathrm{X}$ & $\mathrm{X}$ \\
\hline & Geonoma schottiana Mart. & 39383 & & $\mathrm{X}$ & \\
\hline & Syagrus oleracea (Mart.) Becc. & & & $\mathrm{X}$ & \\
\hline & Syagrus romanzof ana (Cham.) Glassman. & 40331 & $X$ & $\mathrm{X}$ & $\mathrm{X}$ \\
\hline \multicolumn{6}{|l|}{ Asteraceae } \\
\hline & Ambrosia polystachya DC. * & 39154 & & & $\mathrm{X}$ \\
\hline & Baccharis articulata (Lam.) Pers. * & 40241 & & $\mathrm{X}$ & \\
\hline & Baccharis dracunculifolia DC. ${ }^{\mathrm{C}}$ & $39155 ; 39156$ & & $X$ & $\mathrm{X}$ \\
\hline & Baccharis ligustrina DC. & 40236 & & & $\mathrm{X}$ \\
\hline & Baccharis semiserrata DC. * & 39998 & & & $\mathrm{X}$ \\
\hline & Baccharis tarchonanthoides Baker * & 40230 & & & $\mathrm{X}$ \\
\hline & Chromolaena laevigata (Lam.) R.M.King \& H. Rob. * & 40234 & & & $\mathrm{X}$ \\
\hline & Clibadium rotundifolium DC. * & 40883 & & & $\mathrm{X}$ \\
\hline & Eupatorium polystachyum DC. ${ }^{\mathrm{C}}$ & 39999 & & $\mathrm{X}$ & $\mathrm{X}$ \\
\hline & Gochnatia paniculata (Less.) Cabrera * & 39158 & & & $\mathrm{X}$ \\
\hline & Gochnatia polymorpha (Less.) Cabrera ${ }^{\mathrm{C}}$ & $39157 ; 40229$ & & $\mathrm{X}$ & $\mathrm{X}$ \\
\hline & Grazielia intermedia (DC.) R.M.King \& H. Rob. * & 40243 & & & $\mathrm{X}$ \\
\hline & Heterocondylus alatus (Vell.) R. M.King \& H. Rob. & 40226 & $\mathrm{X}$ & & \\
\hline & Koanophyllom thysanolepis (B.L.Rob.) R. M.King \& H. Rob. & 40233 & & $X$ & \\
\hline & Piptocarpha axillaris (Less) Baker & 39159 & & $\mathrm{X}$ & \\
\hline & Piptocarpha macropoda (DC.) Baker & 39160 & $\mathrm{X}$ & & \\
\hline & Senecio brasiliensis (Spreng.) Less. & 39161 & & $X$ & \\
\hline & Symphyopappus polystachyus Baker & 39162 & & $\mathrm{X}$ & \\
\hline & Trixis praestans $\mathrm{Cabr}$ & $40227 ; 40240$ & & $\mathrm{X}$ & $\mathrm{X}$ \\
\hline & Vernonia diffusa Less. ${ }^{\mathrm{C}}$ & $39164 ; 39163$ & $\mathrm{X}$ & $\mathrm{X}$ & $\mathrm{X}$ \\
\hline & Vernonia nitidula Less. & 40231 & & & $\mathrm{X}$ \\
\hline & Vernonia petiolaris DC. ${ }^{\mathrm{C}}$ & 40232 & $\mathrm{X}$ & & \\
\hline & Vernonia phosphorea (Vell.) Semir ${ }^{\mathrm{C}}$ & $40228 ; 40235$ & & $\mathrm{X}$ & $X$ \\
\hline & Vernonia platensis (Spreng.) Less. * & 40242 & & & $\mathrm{X}$ \\
\hline \multicolumn{6}{|c|}{ Bignoniaceae } \\
\hline & Handroanthus botelhensis (A. H. Gentry) S.O.Grose * & 40332 & & & $\mathrm{X}$ \\
\hline
\end{tabular}


Tabela 1. Continuação...

\begin{tabular}{|c|c|c|c|c|c|}
\hline \multirow[t]{2}{*}{ Família } & \multirow[t]{2}{*}{ Espécie } & \multirow[t]{2}{*}{ SPSF } & \multicolumn{3}{|c|}{ Trilha } \\
\hline & & & Ga & Ma & PZ \\
\hline \multicolumn{6}{|c|}{ Bignoniaceae } \\
\hline & Jacaranda caroba (Vell.) A. DC. * & 39166 & & $\mathrm{X}$ & \\
\hline & Jacaranda puberula Cham. & $39167 ; 40000$ & $\mathrm{X}$ & $\mathrm{X}$ & $\mathrm{X}$ \\
\hline & Tabebuia heptaphylla (Vell.) Toledo & 40001 & & $\mathrm{X}$ & $\mathrm{X}$ \\
\hline & Tabebuia ochracea (Cham.) Standl. * & 39168 & & $\mathrm{X}$ & $\mathrm{X}$ \\
\hline \multicolumn{6}{|c|}{ Boraginaceae } \\
\hline & Cordia cf. goeldiana Huber & 41054 & $\mathrm{X}$ & & \\
\hline & Cordia corymbosa Willd. ex Roem. \& Schult. & 39171 & $\mathrm{X}$ & & \\
\hline & Cordia sellowiana Cham. & & $\mathrm{X}$ & & $X$ \\
\hline \multicolumn{6}{|l|}{ Burseraceae } \\
\hline & Protium widgrenii Engl. & & $\mathrm{X}$ & $\mathrm{X}$ & \\
\hline \multicolumn{6}{|c|}{ Cannabaceae } \\
\hline & Celtis iguanaea (Jacq.) Sarg. & 40042 & & $\mathrm{X}$ & \\
\hline & Celtis sp. & 41059 & $\mathrm{X}$ & & \\
\hline & Trema micrantha (L.) Blume. & 39983 & $\mathrm{X}$ & $\mathrm{X}$ & $\mathrm{X}$ \\
\hline \multicolumn{6}{|c|}{ Cardiopteridaceae } \\
\hline & Citronella megaphylla (Miers) R.A. Howard & & $\mathrm{X}$ & & \\
\hline & Citronella paniculata (Mart.) R.A. Howard & & & $\mathrm{X}$ & \\
\hline \multicolumn{6}{|c|}{ Celastraceae } \\
\hline & Maytenus evonymoides Reissek & $39278 ; 39279$ & $\mathrm{X}$ & $\mathrm{X}$ & $\mathrm{X}$ \\
\hline & Maytenus gonoclada Mart. ${ }^{\mathrm{C}}$ & $39280 ; 39281$ & & $\mathrm{X}$ & $\mathrm{X}$ \\
\hline \multicolumn{6}{|l|}{ Clethraceae } \\
\hline & Clethra scabra Pers. ${ }^{\mathrm{C}}$ & 39282 & & $\mathrm{X}$ & $\mathrm{X}$ \\
\hline \multicolumn{6}{|l|}{ Clusiaceae } \\
\hline & Clusia criuva Cambess. & & & & $\mathrm{X}$ \\
\hline & Tovomitopsis paniculata (Spreng.) Planch \& Triana & $39283 ; 39284$ & $\mathrm{X}$ & $\mathrm{X}$ & $\mathrm{X}$ \\
\hline \multicolumn{6}{|c|}{ Cunoniaceae } \\
\hline & Lamanonia ternata Vell. & 39285 & & $\mathrm{X}$ & \\
\hline \multicolumn{6}{|l|}{ Ebenaceae } \\
\hline & Diospyros inconstans Jacq. & & & $\mathrm{X}$ & \\
\hline \multicolumn{6}{|c|}{ Elaeocarpaceae } \\
\hline & Sloanea guianensis (Aubl.) Benth. & $39286 ; 39287$ & $\mathrm{X}$ & $\mathrm{X}$ & $\mathrm{X}$ \\
\hline \multicolumn{6}{|c|}{ Euphorbiaceae } \\
\hline & Alchornea sidifolia Müll. Arq. & 40005 & $\mathrm{X}$ & & $\mathrm{X}$ \\
\hline & Alchornea triplinervia (Spreng.) Müll. Arg. & 39288 & $\mathrm{X}$ & $\mathrm{X}$ & $\mathrm{X}$ \\
\hline & Croton floribundus Lund ex. Didr. & $39289 ; 39290$ & $\mathrm{X}$ & $\mathrm{X}$ & $X$ \\
\hline & Croton macrobothrys Baill. & 40006 & $\mathrm{X}$ & $\mathrm{X}$ & $\mathrm{X}$ \\
\hline & Croton salutaris Casar. & 40007 & & $\mathrm{X}$ & \\
\hline & Croton urucurana Baill & & $\mathrm{X}$ & & \\
\hline & Sapium glandulosum (L.) Morong. & & & $\mathrm{X}$ & \\
\hline & Tetrorchidium rubrivenium Poepp. & $39294 ; 39295$ & $\mathrm{X}$ & $\mathrm{X}$ & \\
\hline \multicolumn{6}{|c|}{ Fabaceae (Caesalpinioideae) } \\
\hline & Cassia ferruginea (Schrader) Schrader ex DC. & 39173 & $\mathrm{X}$ & $\mathrm{X}$ & $X$ \\
\hline & Copaifera langsdor $i$ Desf. & & & $\mathrm{X}$ & \\
\hline & Senna angulata (Vogel) H. S. Irwin \& Barneby & $39274 ; 40003$ & $\mathrm{X}$ & $\mathrm{X}$ & \\
\hline & Senna multijuga (Rich.) H. S. Irwin \& Barneby & $39275 ; 40004$ & & $\mathrm{X}$ & $\mathrm{X}$ \\
\hline & Senna pendula Willd. ${ }^{\mathrm{C}}$ & 39276 & & & $\mathrm{X}$ \\
\hline & Senna splendida (Vogel) H.S. Irwin \& Barneby & 39277 & & $\mathrm{X}$ & \\
\hline \multicolumn{6}{|c|}{ Fabaceae (Faboideae) } \\
\hline & Andira anthelmia (Vell) J.F. Macbr. & & $\mathrm{X}$ & $\mathrm{X}$ & \\
\hline & Centrolobium tomentosum Guill. ex Benth. & 39296 & $\mathrm{X}$ & & $\mathrm{X}$ \\
\hline & Crotalaria anagyroides Kunth. * & 40008 & & & $\mathrm{X}$ \\
\hline & Crotalaria sp. & 41056 & & $\mathrm{X}$ & \\
\hline
\end{tabular}


Tabela 1. Continuação...

\begin{tabular}{|c|c|c|c|c|c|}
\hline \multirow[t]{2}{*}{ Família } & \multirow[t]{2}{*}{ Espécie } & \multirow[t]{2}{*}{ SPSF } & \multicolumn{3}{|c|}{ Trilha } \\
\hline & & & Ga & Ma & PZ \\
\hline \multicolumn{6}{|c|}{ Fabaceae (Faboideae) } \\
\hline & Dalbergia brasiliensis Vogel & & $\mathrm{X}$ & & \\
\hline & Dalbergia frutescens (Vell.) Britton & & & & $\mathrm{X}$ \\
\hline & Erythrina sp. & 41055 & & & $\mathrm{X}$ \\
\hline & Lonchocarpus subglaucescens Mart. ex Benth & 39298 & & $\mathrm{X}$ & $\mathrm{X}$ \\
\hline & Machaerium aculeatum (Vell.) Stellfeld & 39299 & & & $\mathrm{X}$ \\
\hline & Machaerium nyctitans (Vell.) Benth. & 39300 & $X$ & $\mathrm{X}$ & $\mathrm{X}$ \\
\hline & Machaerium stipitatum (DC.) Vogel & & & $\mathrm{X}$ & $\mathrm{X}$ \\
\hline & Machaerium villosum Vogel. ${ }^{\mathrm{c}}$ & 39301 & $\mathrm{X}$ & $\mathrm{X}$ & $\mathrm{X}$ \\
\hline & Ormosia arborea (Vell.) Harms. & 40010 & & & $\mathrm{X}$ \\
\hline & Platymiscium floribundum Vogel. & $39303 ; 39304$ & $X$ & $\mathrm{X}$ & $\mathrm{X}$ \\
\hline & Pterocarpus rohrii Vahl & 39305 & $\mathrm{X}$ & & \\
\hline \multicolumn{6}{|c|}{ Fabaceae (Mimosoideae) } \\
\hline & Albizia polycephala (Benth.) Killip & 40047 & $\mathrm{X}$ & & \\
\hline & Anadenanthera colubrina (Vell.) Brenan & 39342 & & & $\mathrm{X}$ \\
\hline & Anadenanthera peregrina (L.) Speg. & 40017 & & $\mathrm{X}$ & \\
\hline & Inga marginata Kunth. & 39343 & & $\mathrm{X}$ & $X$ \\
\hline & Inga sessilis (Vell.) Brenan & $39344 ; 39345$ & & $\mathrm{X}$ & $\mathrm{X}$ \\
\hline & Leucochloron incuriale (Vell.) Barneby \& J.W.Grimes * & 40018 & & & $\mathrm{X}$ \\
\hline & Mimosa daleoides Benth. * & $40019 ; 40020$ & & $\mathrm{X}$ & $X$ \\
\hline & Piptadenia gonoacantha (Mart.) J. F. Macbr. & 39346 & $X$ & $\mathrm{X}$ & $\mathrm{X}$ \\
\hline & Pithecellobium langsdor $i$ Benth. & 40021 & & & $\mathrm{X}$ \\
\hline \multicolumn{6}{|l|}{ Lamiaceae } \\
\hline & Aegiphila sellowiana Cham. & 39986 & & $\mathrm{X}$ & $X$ \\
\hline & Vitex polygama Cham. ${ }^{\mathrm{C}}$ & 39988 & $X$ & & $\mathrm{X}$ \\
\hline \multicolumn{6}{|l|}{ Lauraceae } \\
\hline & Beilschmiedia emarginata (Meisn.) Kosterm. & 39309 & & $\mathrm{X}$ & \\
\hline & Cryptocarya mandioccana Meisn. & 39310 & & & $\mathrm{X}$ \\
\hline & Endlicheria paniculata (Spreng.) J. F. Macbr. & 39311 & $\mathrm{X}$ & $\mathrm{X}$ & $\mathrm{X}$ \\
\hline & Nectandra debilis $\mathrm{Mez}$ & $40900 ; 40901$ & & $\mathrm{X}$ & $X$ \\
\hline & Nectandra lanceolata Nees. & 39313 & & $\mathrm{X}$ & \\
\hline & Nectandra membranacea (Spreng.) Hassl. & 39314 & $X$ & $\mathrm{X}$ & $\mathrm{X}$ \\
\hline & Nectandra nitidula Nees. \& Mart. & 39315 & $\mathrm{X}$ & $\mathrm{X}$ & $\mathrm{X}$ \\
\hline & Nectandra oppositifolia Nees. \& Mart. & 39316 & $\mathrm{X}$ & $\mathrm{X}$ & $\mathrm{X}$ \\
\hline & Ocotea aciphylla (Nees.) Mez. & 39317 & & $\mathrm{X}$ & $X$ \\
\hline & Ocotea glaziovii $\mathrm{Mez}$ & 39318 & $\mathrm{X}$ & & $\mathrm{X}$ \\
\hline & Ocotea nutans (Nees) Mez & $39319 ; 39320$ & & & $\mathrm{X}$ \\
\hline & Ocotea puberula (Rich.) Nees & 39321 & & $\mathrm{X}$ & $\mathrm{X}$ \\
\hline & Ocotea pulchella (Nees) $\mathrm{Mez}^{\mathrm{C}}$ & 39322 & & & $\mathrm{X}$ \\
\hline & Ocotea teleiandra (Meisn.) Mez & $39323 ; 39324$ & $X$ & & $\mathrm{X}$ \\
\hline & Ocotea tristis (Nees \& Mart.) $\mathrm{Mez}^{\mathrm{C}}$ & 41057 & & & $\mathrm{X}$ \\
\hline & Persea willdenovii Kosterm. & & & $X$ & $\mathrm{X}$ \\
\hline \multicolumn{6}{|c|}{ Lecythidaceae } \\
\hline & Cariniana estrellensis (Raddi) Kuntze & 39325 & & $\mathrm{X}$ & $\mathrm{X}$ \\
\hline \multicolumn{6}{|l|}{ Lythraceae } \\
\hline & Lafoensia pacari A. St. - Hil. ${ }^{\text {C }}$ & $39327 ; 40011$ & & & $\mathrm{X}$ \\
\hline \multicolumn{6}{|c|}{ Malpighiaceae } \\
\hline & Byrsonima intermedia A. Juss. * & 40013 & & & $\mathrm{X}$ \\
\hline & Byrsonima ligustrifolia Saint-Hilaire * & 40012 & & & $\mathrm{X}$ \\
\hline & Heteropterys umbellata A. Juss. * & 40014 & & & $\mathrm{X}$ \\
\hline \multicolumn{6}{|l|}{ Malvaceae } \\
\hline & Ceiba speciosa (A. St. - Hil.) Ravenna & 40002 & & $\mathrm{X}$ & $\mathrm{X}$ \\
\hline
\end{tabular}


Tabela 1. Continuação...

\begin{tabular}{|c|c|c|c|c|c|}
\hline \multirow[t]{2}{*}{ Família } & \multirow[t]{2}{*}{ Espécie } & \multirow[t]{2}{*}{ SPSF } & \multicolumn{3}{|c|}{ Trilha } \\
\hline & & & Ga & Ma & $\mathbf{P Z}$ \\
\hline \multicolumn{6}{|l|}{ Malvaceae } \\
\hline & Luehea divaricata Mart. & & & $X$ & $\mathrm{X}$ \\
\hline & Luehea grandiflora Mart. & 39982 & $\mathrm{X}$ & $\mathrm{X}$ & $\mathrm{X}$ \\
\hline & Pseudobombax grandiflorum (Cav.) A. Robyns & $39308 ; 39170$ & & & $\mathrm{X}$ \\
\hline & Sida carpinifolia Bourg. ex Griseb & 39328 & $\mathrm{X}$ & $\mathrm{X}$ & \\
\hline & Sida sp. 1 & 41007 & & & $\mathrm{X}$ \\
\hline & Sida sp. 2 & 41006 & & & $\mathrm{X}$ \\
\hline & Sida sp. 3 & 41005 & $\mathrm{X}$ & & \\
\hline \multicolumn{6}{|c|}{ Melastomataceae } \\
\hline & Leandra acutiflora (Naudin) Cogn. & $39329 ; 40015$ & $X$ & & \\
\hline & Leandra aurea (Cham.) Cogn. & 39331 & & & $\mathrm{X}$ \\
\hline & Leandra bergiana Cogn. & 39332 & $\mathrm{X}$ & & $\mathrm{X}$ \\
\hline & Leandra fragilis Cogn. & 39333 & $X$ & & $\mathrm{X}$ \\
\hline & Leandra mosenii Cogn. & 39334 & $\mathrm{X}$ & $\mathrm{X}$ & $\mathrm{X}$ \\
\hline & Miconia budlejoides Triana & 40016 & $\mathrm{X}$ & & \\
\hline & Miconia cabussu Hoehne & 39335 & & $\mathrm{X}$ & $\mathrm{X}$ \\
\hline & Miconia castaneiflora Naudin & 40194 & $\mathrm{X}$ & & \\
\hline & Miconia cinnamomifolia (DC.) Naudin & 39336 & $\mathrm{X}$ & $\mathrm{X}$ & $\mathrm{X}$ \\
\hline & Miconia hymenonervia (Raddi) $\operatorname{Cogn}^{\mathrm{C}}$ & 39337 & $\mathrm{X}$ & $\mathrm{X}$ & $\mathrm{X}$ \\
\hline & Miconia latecrenata (DC.) Naudin & 39338 & & $\mathrm{X}$ & \\
\hline & Miconia ligustroides (DC.) Naudin & 39339 & & & $\mathrm{X}$ \\
\hline & Miconia petropolitana Cogn. & 39330 & $\mathrm{X}$ & & \\
\hline & Mouriri chamissoana Cogn. in Mart. & & & $\mathrm{X}$ & $\mathrm{X}$ \\
\hline & Ossaea amygdaloides Triana & 40192 & & $\mathrm{X}$ & \\
\hline & Tibouchina cerastifolia Cogn. & 40193 & & $\mathrm{X}$ & \\
\hline & Tibouchina chamissoana Cogn. * & $40046 ; 40195$ & & & $\mathrm{X}$ \\
\hline & Tibouchina multiceps Cogn. & 39340 & & & $\mathrm{X}$ \\
\hline & Tibouchina pulchra (Cham.) Cogn. * & & & $\mathrm{X}$ & \\
\hline & Tibouchina sellowiana Cogn. ${ }^{\mathrm{C}}$ & $39341 ; 40045$ & $\mathrm{X}$ & $\mathrm{X}$ & $\mathrm{X}$ \\
\hline \multicolumn{6}{|l|}{ Meliaceae } \\
\hline & Cabralea canjerana (Vell.) Mart. & $40102 ; 40103$ & $\mathrm{X}$ & $\mathrm{X}$ & $\mathrm{X}$ \\
\hline & Cedrela ssilis Vell. & & & $\mathrm{X}$ & $\mathrm{X}$ \\
\hline & Cedrela odorata $\mathrm{L}$ & 40101 & $\mathrm{X}$ & & $\mathrm{X}$ \\
\hline & Guarea macrophylla subsp. tuberculata (Vell.) T.D. Penn. & $40098 ; 40097$ & $\mathrm{X}$ & $\mathrm{X}$ & $\mathrm{X}$ \\
\hline \multicolumn{6}{|c|}{ Monimiaceae } \\
\hline & Mollinedia oligotricha Perkins & $39347 ; 40022$ & $X$ & & \\
\hline & Mollinedia schottiana (Spreng.) Perkins & 39348 & & $\mathrm{X}$ & $\mathrm{X}$ \\
\hline & Mollinedia triflora (Spreng.) Tul. & $40023 ; 40024$ & $X$ & & \\
\hline \multicolumn{6}{|l|}{ Moraceae } \\
\hline & Ficus insipida Willd. & 39350 & $\mathrm{X}$ & $\mathrm{X}$ & $\mathrm{X}$ \\
\hline & Ficus luschnathiana (Miq.) Miq. & 40025 & $\mathrm{X}$ & $\mathrm{X}$ & \\
\hline & Sorocea bonplandii (Baill.) W. C. Burger, Lanj. \& Wess. Boer. & 39351 & $\mathrm{X}$ & $\mathrm{X}$ & $\mathrm{X}$ \\
\hline \multicolumn{6}{|c|}{ Myrsinaceae } \\
\hline & Rapanea ferruginea (Ruiz \& Pav.) $\mathrm{Mez}^{\mathrm{C}}$ & $39352 ; 39353$ & & $\mathrm{X}$ & $\mathrm{X}$ \\
\hline & Rapanea lancifolia (Mart.) Mez & 40026 & & & $\mathrm{X}$ \\
\hline & Rapanea umbellata (Mart.) $\mathrm{Mez}^{\mathrm{C}}$ & $39354 ; 39355$ & & $\mathrm{X}$ & $\mathrm{X}$ \\
\hline \multicolumn{6}{|l|}{ Myrtaceae } \\
\hline & Calyptranthes grandifolia $\mathrm{O}$. Berg. & 39356 & & $\mathrm{X}$ & \\
\hline & Campomanesia guazumifolia (Cambess.) O.Berg. & & & & $\mathrm{X}$ \\
\hline & Campomanesia pubescens (DC.) O. Berg. ${ }^{\mathrm{C}}$ & 39357 & & $\mathrm{X}$ & $\mathrm{X}$ \\
\hline & Campomanesia xanthocarpa (Mart.) O. Berg. & 39358 & $\mathrm{X}$ & $\mathrm{X}$ & \\
\hline & Eugenia beaurepairiana (Kiaersk.) D. Legrand & 39359 & & & $\mathrm{X}$ \\
\hline & Eugenia cerasiflora Miq. & 39360 & $\mathrm{X}$ & $\mathrm{X}$ & $\mathrm{X}$ \\
\hline & Eugenia involucrata O. Berg. & $39361 ; 39362$ & & $\mathrm{X}$ & $\mathrm{X}$ \\
\hline
\end{tabular}


Tabela 1. Continuação...

\begin{tabular}{|c|c|c|c|c|c|}
\hline \multirow[t]{2}{*}{ Família } & \multirow[t]{2}{*}{ Espécie } & \multirow[t]{2}{*}{ SPSF } & \multicolumn{3}{|c|}{ Trilha } \\
\hline & & & Ga & Ma & $\mathbf{P Z}$ \\
\hline \multicolumn{6}{|l|}{ Myrtaceae } \\
\hline & Eugenia aff. involucrata $\mathrm{O}$. Berg. & & & $\mathrm{X}$ & \\
\hline & Eugenia kleinii D. Legrand. ${ }^{\mathrm{C}}$ & $39363 ; 40027$ & & & $\mathrm{X}$ \\
\hline & Eugenia ligustrina Cambess. & 39364 & & $\mathrm{X}$ & $\mathrm{X}$ \\
\hline & Eugenia prasina $\mathrm{O} . \mathrm{Berg}$ & $39365 ; 39366$ & $\mathrm{X}$ & $\mathrm{X}$ & \\
\hline & Eugenia uniflora $\mathrm{L}$. & & $\mathrm{X}$ & & \\
\hline & Gomidesia anacardiaefolia (Gardner) O. Berg. & & $\mathrm{X}$ & & \\
\hline & Gomidesia tijucensis (Kiaersk.) D. Legrand. & $39367 ; 39368$ & & $\mathrm{X}$ & \\
\hline & Myrceugenia campestris (DC.) D. Legrand \& Kausel & $39369 ; 39370$ & $\mathrm{X}$ & $\mathrm{X}$ & $\mathrm{X}$ \\
\hline & Myrcia fallax (Rich.) DC. ${ }^{\mathrm{C}}$ & 39371 & $\mathrm{X}$ & $\mathrm{X}$ & $\mathrm{X}$ \\
\hline & Myrcia rostrata DC. ${ }^{\mathrm{C}}$ & 39372 & & $\mathrm{X}$ & $\mathrm{X}$ \\
\hline & Myrcia tomentosa (Aubl.) DC. ${ }^{\mathrm{C}}$ & & & & $\mathrm{X}$ \\
\hline & Myrciaria floribunda (H. Westex Willd.) O. Berg. & & $\mathrm{X}$ & & \\
\hline & Myrciaria tenella (DC.) O. Berg. & & & $\mathrm{X}$ & $\mathrm{X}$ \\
\hline & Pimenta pseudocaryophyllus (Gomes) Landrum ${ }^{\mathrm{C}}$ & 39373 & & & $\mathrm{X}$ \\
\hline & Plinia glomerata (O. Berg) Amshoff & 39374 & $\mathrm{X}$ & & $\mathrm{X}$ \\
\hline & Plinia rivularis (Cambess.) & & & $\mathrm{X}$ & \\
\hline & Plinia trunciflora (O. Berg) Kausel & & & $\mathrm{X}$ & \\
\hline & Psidium guineense $\mathrm{Sw}{ }^{\mathrm{C}}$ & $39375 ; 39376$ & & $\mathrm{X}$ & $\mathrm{X}$ \\
\hline & Siphoneugenia densiflora O. Berg. & $39377 ; 39378$ & & $\mathrm{X}$ & $\mathrm{X}$ \\
\hline \multicolumn{6}{|c|}{ Nyctaginaceae } \\
\hline & Guapira opposita (Vell.) Reitz & 39379 & $\mathrm{X}$ & $\mathrm{X}$ & $\mathrm{X}$ \\
\hline \multicolumn{6}{|l|}{ Ochnaceae } \\
\hline & Ouratea multiflora Engl. & 40084 & & $\mathrm{X}$ & \\
\hline \multicolumn{6}{|l|}{ Olacaceae } \\
\hline & Heisteria silvianii Schwacke & 39380 & $\mathrm{X}$ & $\mathrm{X}$ & $\mathrm{X}$ \\
\hline \multicolumn{6}{|l|}{ Oleaceae } \\
\hline & Chionanthus liformis (Vell.) P. S. Green. & 39382 & & $\mathrm{X}$ & \\
\hline \multicolumn{6}{|l|}{ Peraceae } \\
\hline & Pera glabrata (Schott.) Poepp ex Baill. & 39292 & $\mathrm{X}$ & $\mathrm{X}$ & $\mathrm{X}$ \\
\hline \multicolumn{6}{|c|}{ Phyllanthaceae } \\
\hline & Hyeronima alchorneoides Allemão & & & & $\mathrm{X}$ \\
\hline \multicolumn{6}{|c|}{ Phytolaccaceae } \\
\hline & Seguieria floribunda Benth. & 39384 & $\mathrm{X}$ & & $\mathrm{X}$ \\
\hline \multicolumn{6}{|c|}{ Picramniaceae } \\
\hline & Picramnia glazioviana Engl. & 40028 & $\mathrm{X}$ & $\mathrm{X}$ & \\
\hline \multicolumn{6}{|l|}{ Piperaceae } \\
\hline & Piper aduncum $\mathrm{L}$. & $\begin{array}{c}39385 ; 40203 ; 40204 ; \\
40206\end{array}$ & $\mathrm{X}$ & $\mathrm{X}$ & $X$ \\
\hline & Piper caldense C. DC. & 40200 & $\mathrm{X}$ & & \\
\hline & Piper cernuum Vell. & 40029 & $\mathrm{X}$ & & $\mathrm{X}$ \\
\hline & Piper dilatatum Rich. & 40201 & & & $\mathrm{X}$ \\
\hline & Piper aff. hispidinervum C. DC & 40202 & & & $\mathrm{X}$ \\
\hline & Piper lanceolatum Ruiz \& Pav. & 40205 & $\mathrm{X}$ & & \\
\hline & Piper martiana Miq. & 40197; 40198; 40199 & $\mathrm{X}$ & & \\
\hline & Piper permucronatum Yunck. & 40048 & $\mathrm{X}$ & $\mathrm{X}$ & $\mathrm{X}$ \\
\hline \multicolumn{6}{|c|}{ Polygonaceae } \\
\hline & Coccoloba warmingii Meisn. & $40030 ; 40031$ & & $\mathrm{X}$ & $\mathrm{X}$ \\
\hline \multicolumn{6}{|l|}{ Proteaceae } \\
\hline & Euplassa cantareirae Sleumer & & & $\mathrm{X}$ & \\
\hline & Roupala brasiliensis Klotzsch. & 39388 & & $\mathrm{X}$ & \\
\hline \multicolumn{6}{|l|}{ Rosaceae } \\
\hline & Prunus myrtifolia (L.) Urb. & 39392 & $X$ & $\mathrm{X}$ & \\
\hline & Rubus brasiliensis Mart. & 39393 & & & $\mathrm{X}$ \\
\hline
\end{tabular}


Tabela 1. Continuação...

\begin{tabular}{|c|c|c|c|c|c|}
\hline \multirow[t]{2}{*}{ Família } & \multirow[t]{2}{*}{ Espécie } & \multirow[t]{2}{*}{ SPSF } & \multicolumn{3}{|c|}{ Trilha } \\
\hline & & & Ga & Ma & $\mathbf{P Z}$ \\
\hline \multicolumn{6}{|l|}{ Rubiaceae } \\
\hline & Alibertia concolor (Cham.) K. Schum. & 40032 & & $\mathrm{X}$ & \\
\hline & Alibertia myrciifolia Spruce ex. Schum. & 39952 & & $\mathrm{X}$ & \\
\hline & Alseis floribunda Schott & & & $\mathrm{X}$ & \\
\hline & Bathysa meridionalis L. B. SM. \& Downs & 39953 & $\mathrm{X}$ & $\mathrm{X}$ & $\mathrm{X}$ \\
\hline & Faramea montevidensis (Cham. \& Schltdl.) DC. & 40034 & & $\mathrm{X}$ & $\mathrm{X}$ \\
\hline & Guettarda viburnoides Cham. \& Schltdl. & & & $\mathrm{X}$ & $\mathrm{X}$ \\
\hline & Palicourea marcgravii A. St.-Hil. & & & & $\mathrm{X}$ \\
\hline & Posoqueria acutifolia Mart. & $39954 ; 40035$ & & $\mathrm{X}$ & \\
\hline & Psychotria carthagenensis Jacg. & 39956 & $\mathrm{X}$ & $\mathrm{X}$ & \\
\hline & Psychotria forsteronioides Müll. Arg. & $39957 ; 40036$ & $\mathrm{X}$ & $\mathrm{X}$ & $\mathrm{X}$ \\
\hline & Psychotria longipes Müll. Arg. & $39958 ; 40037$ & $\mathrm{X}$ & $\mathrm{X}$ & $\mathrm{X}$ \\
\hline & Psychotria sessilis (Vell.) Müll. Arg. & 40038 & & & $\mathrm{X}$ \\
\hline & Psychotria suterella Müll. Arg. & 39959 & $\mathrm{X}$ & $\mathrm{X}$ & $\mathrm{X}$ \\
\hline & Randia armata (Sw.) DC. & 39960 & & & $\mathrm{X}$ \\
\hline & Rudgea gardenioides (Cham.) Müll. Arg. & & & $\mathrm{X}$ & \\
\hline \multicolumn{6}{|l|}{ Rutaceae } \\
\hline & Balfourodendron riedelianum (Engl.) Engl. & 39961 & & & $\mathrm{X}$ \\
\hline & Esenbeckia grandiflora Mart. & $39962 ; 40039$ & & $\mathrm{X}$ & $\mathrm{X}$ \\
\hline & Zanthoxylum rhoifolium Lam. & & $\mathrm{X}$ & $\mathrm{X}$ & $\mathrm{X}$ \\
\hline \multicolumn{6}{|l|}{ Salicaceae } \\
\hline & Casearia decandra Jacq. & 39306 & $\mathrm{X}$ & $\mathrm{X}$ & \\
\hline & Casearia obliqua Spreng. & & & & $\mathrm{X}$ \\
\hline & Casearia sylvestris $\mathrm{Sw}{ }^{\mathrm{C}}$ & 39307 & $\mathrm{X}$ & $\mathrm{X}$ & $X$ \\
\hline \multicolumn{6}{|c|}{ Sapindaceae } \\
\hline & Allophylus edulis (A. St. - Hil. Cambess. \& A. Juss.) Radlk & 39966 & $\mathrm{X}$ & $\mathrm{X}$ & $\mathrm{X}$ \\
\hline & Cupania emarginata Cambess. & $39967 ; 40040$ & $\mathrm{X}$ & $\mathrm{X}$ & \\
\hline & Cupania oblongifolia Mart. & 39968 & $\mathrm{X}$ & $\mathrm{X}$ & $\mathrm{X}$ \\
\hline & Cupania vernalis Cambess. * & & & & $\mathrm{X}$ \\
\hline & Dodonaea viscosa $\mathrm{Sm} .^{\mathrm{C}}$ & $39969 ; 39970$ & & $\mathrm{X}$ & $\mathrm{X}$ \\
\hline & Matayba elaeagnoides Radlk. & & $\mathrm{X}$ & $\mathrm{X}$ & \\
\hline \multicolumn{6}{|l|}{ Sapotaceae } \\
\hline & Pouteria caimito (Ruiz \& Pav.) Radlk. & 39971 & & $\mathrm{X}$ & \\
\hline \multicolumn{6}{|c|}{ Scrophulariaceae } \\
\hline & Buddleia brasiliensis Jacq. & 39326 & & $\mathrm{X}$ & \\
\hline \multicolumn{6}{|l|}{ Solanaceae } \\
\hline & Aureliana fasciculata (Vell.) Sendtn. & $40088 ; 40095$ & $\mathrm{X}$ & $\mathrm{X}$ & \\
\hline & Capsicum flexuosum Sendtn. & 40085 & $\mathrm{X}$ & & \\
\hline & Capsicum mirabile Mart. & & $\mathrm{X}$ & & $\mathrm{X}$ \\
\hline & Cestrum intermedium Sendtn. ${ }^{\mathrm{C}}$ & $40091 ; 40090$ & & $\mathrm{X}$ & $\mathrm{X}$ \\
\hline & Cestrum schlechtendalii G.Don & $40092 ; 40260$ & $\mathrm{X}$ & & \\
\hline & Cestrum sp. & 40089 & & $\mathrm{X}$ & \\
\hline & Sessea brasiliensis Toledo & $40041 ; 40093$ & & $\mathrm{X}$ & $\mathrm{X}$ \\
\hline & Solanum bullatum Vell. & $39972 ; 40186$ & $\mathrm{X}$ & $\mathrm{X}$ & \\
\hline & Solanum concinnum Sendtn. & $39973 ; 39974$ & & $\mathrm{X}$ & \\
\hline & Solanum mauritianum Scop. & 39975 & & $\mathrm{X}$ & \\
\hline & Solanum pseudoquina A. St.-Hil. & $39976 ; 39977$ & & $\mathrm{X}$ & \\
\hline & Solanum variabile Mart. $^{\mathrm{C}}$ & $39978 ; 39979$ & & $\mathrm{X}$ & $X$ \\
\hline \multicolumn{6}{|l|}{ Styracaceae } \\
\hline & Styrax acuminatus Pohl. & 39980 & & $\mathrm{X}$ & \\
\hline \multicolumn{6}{|c|}{ Symplocaceae } \\
\hline & Symplocos falcata Brand & & & & $\mathrm{X}$ \\
\hline \multicolumn{6}{|l|}{ Urticaceae } \\
\hline & Boehmeria caudata Sw. & 39984 & $X$ & $\mathrm{X}$ & $X$ \\
\hline & Cecropia glaziovi Snethl. & & $\mathrm{X}$ & $\mathrm{X}$ & $\mathrm{X}$ \\
\hline
\end{tabular}


Tabela 1. Continuação...

\begin{tabular}{|c|c|c|c|c|c|}
\hline \multirow[t]{2}{*}{ Família } & \multirow[t]{2}{*}{ Espécie } & \multirow[t]{2}{*}{ SPSF } & \multicolumn{3}{|c|}{ Trilha } \\
\hline & & & Ga & Ma & $\mathbf{P Z}$ \\
\hline \multicolumn{6}{|l|}{ Urticaceae } \\
\hline & Cecropia hololeuca Miq. & & $\mathrm{X}$ & & $\mathrm{X}$ \\
\hline & Urera mitis Miq. & 39985 & & $\mathrm{X}$ & $\mathrm{X}$ \\
\hline \multicolumn{6}{|l|}{ Verbenaceae } \\
\hline & Citharexylum myrianthum Cham. & & $\mathrm{X}$ & & \\
\hline & Lantana camara $\mathrm{L} .{ }^{\mathrm{C}}$ & 39987 & & $\mathrm{X}$ & $\mathrm{X}$ \\
\hline \multicolumn{6}{|c|}{ Vochysiaceae } \\
\hline & Qualea dichotoma (Mart.) Warm. * & 40043 & & & $\mathrm{X}$ \\
\hline & Vochysia magni ca Warm. & 40044 & & $\mathrm{X}$ & $\mathrm{X}$ \\
\hline & Vochysia selloi Warm. & 40049 & & $\mathrm{X}$ & \\
\hline & Total de espécies: 262 & & 107 & 162 & 169 \\
\hline
\end{tabular}

Além das áreas com estrutura tipicamente florestal, ou seja, com estrato arbóreo predominante, o PEJ apresenta um trecho onde a vegetação é caracterizada pela abundância de plantas herbáceas em áreas com afloramentos de rocha e solo raso, chamado por Ab'Sáber (2003) de "espinhaço quartzítico" e referido aqui como "campo". Essa região ocupa cerca de 37 ha e grande parte situa-se na porção mais alta do Parque, sujeita à ocorrência de neblina, condição comum nos campos de altitude e matas nebulares (Garcia \& Pirani 2005). Fisionomicamente, essa área assemelha-se mais a um mosaico de diferentes fisionomias de cerrado ou mesmo aos campos de altitude do que a outras formações. Além do estrato herbáceo, ocorrem arbustos e árvores esparsos, dos quais muitos com pequeno porte e tronco suberoso.

Locais com afloramentos rochosos e vegetação de características xeromórficas já foram relatados também para a Serra do Japi, no município de Jundiaí, a 60 km da capital (Leitão-Filho 1992) e para o Parque Estadual da Serra do Mar - núcleo Curucutu, na região sul do município de São Paulo (Garcia \& Pirani 2005). Analisando-se o trabalho de Leitão-Filho (1992), nota-se que o componente herbáceo da vegetação encontrada no PEJ não parece ser o mesmo descrito para a Serra do Japi, onde dentre as famílias predominantes destacam-se Bromeliaceae, Piperaceae e Cactaceae, não observadas na área de campo do Jaraguá. Por outro lado, entre as famílias de árvores e arbustos mais comuns citadas pelo autor para os lajedos rochosos do Japi estão Asteraceae, Myrtaceae e Melastomataceae, que figuram entre as cinco famílias de maior riqueza na área de campo do PEJ (Tabela 1). Em relação à vegetação descrita por Garcia \& Pirani (2005), apesar da semelhança fisionômica, foram observadas apenas oito espécies em comum à flora apresentada pelos autores para as áreas de campo de altitude e "mata baixa", fato que sugere uma baixa similaridade entre os campos do PEJ e os campos de altitude remanescentes das serras paulistas.

A existência de vegetação campestre em meio a uma matriz florestal foi mencionada também por Meira-Neto et al. (1989) para o Parque Estadual da Grota Funda, em Atibaia, a cerca de 70 km de São Paulo. Porém, a lista florística foi apresentada para todo o Parque, sem que houvesse detalhamento dessa vegetação em particular, o que impediu a comparação dessa área com o campo do PEJ.

Especificamente no campo, foram amostradas 55 espécies arbustivas e arbóreas pertencentes a 41 gêneros e 18 famílias, das quais 22 ocorreram exclusivamente nessa área. A família com maior riqueza foi Asteraceae (15 espécies), seguida por Myrtaceae (7), Fabaceae (5) e Melastomataceae (4). Além das espécies de floresta ombrófila densa e de floresta estacional semidecidual, ocorreram também espécies típicas de cerrado, como Byrsonima intermedia A. Juss., Gochnatia polymorpha (Less.) Cabrera, Psidium guineense Sw., Tabebuia ochracea (Cham.) Standl., entre outras (Durigan et al. 2004). Dentre as espécies herbáceas mais abundantes foram observadas espécies exóticas invasoras, como Urochloa decumbens (Stapf) R.D. Webster (braquiária) e Melinis minutiflora P. Beauv. (capim-gordura). Essas espécies, comuns em áreas antropizadas de cerrado (Ribeiro \& Walter 1998), possivelmente se estabelecem mais rápido que as espécies nativas após os incêndios, que ocorrem quase todo ano nessa região. Em menor abundância ocorre também o sapê (Imperata brasiliensis Trin.), espécie nativa de campos (Longhi-Wagner et al. 2001).

Embora fisionomicamente a área de campo possa ser considerada semelhante também aos campos de altitude, floristicamente essa área parece ser mais próxima a algumas formações do cerrado sensu stricto, como o cerrado denso e o cerrado típico (Ribeiro \& Walter 1998). Comparando-se sua flora com as lista de espécies arbustivas e arbóreas com binômio completo registrada para o Parque Estadual do Juquery (Baitello et al. dados não publicados), que fica distante cerca de $23 \mathrm{~km}$ em linha reta do PEJ e cuja formação predominante é de cerrado (Kronka et al. 2005), foram constatadas 26 espécies em comum, o que corresponde a quase $50 \%$ das espécies amostradas.

Relatos da possível existência de cerrado nas partes altas dos morros no Planalto Paulistano são antigos e apontam como algumas das justificativas para esse padrão a presença de solos de baixa fertilidade e a existência de linhas de pedra (stone lines) em camadas superficiais $(20-30 \mathrm{~cm})$ do solo, estrutura que dificultaria o desenvolvimento de árvores de maior porte e, conseqüentemente, o estabelecimento de uma vegetação florestal como a que predomina nos mares de morros da região (Ab'Sáber 1970a, b).

Em resposta às flutuações climáticas do Quaternário, no sudeste brasileiro, entre 10.000 e 5.500 anos AP, o cerrado se expandiu para o leste em direção ao Oceano Atlântico; no final do Holoceno (5.500 AP), o clima ficou mais quente e úmido, culminando na expansão das florestas (Behling 1998). As áreas remanescentes de cerrado no estado de São Paulo seriam, portanto, relictos de uma era de clima mais seco nessa região (Durigan 2006). Há evidências recentes de que o avanço das florestas sobre o cerrado ainda esteja ocorrendo, não apenas por condicionantes climáticas, mas também, pela diminuição das queimadas (Durigan 2006), o que explicaria em parte a existência de espécies de floresta estacional e ombrófila nos campos do PEJ.

Embora esses registros sugiram que vegetação de campo do PEJ é originária do cerrado, não se deve descartar a hipótese de que essa fitofisionomia seja um produto de alterações antrópicas associadas a uma melhor adaptação local de algumas espécies e/ou a condições edáficas. Certas particularidades geomorfológicas deram origem a outros tipos de solo na área de campo, provavelmente Cambissolos 
Háplicos e Neossolos Litólicos (M. Rossi, comunicação pessoal), o que poderia restringir o estabelecimento de algumas espécies. A proximidade do Parque Estadual do Juquery poderia explicar a ocupação de espécies de cerrado, que estariam colonizando a área em virtude de sua melhor adaptação a tais condições edáficas.

Entretanto, as informações disponíveis até o momento não são suficientes para que se possa compreender e determinar seguramente a classificação fitogeográfica da vegetação de campo do PEJ. Essa incerteza sobre as áreas de campo parece ser comum e justifica-se por suas pequenas extensões, pelo seu padrão fragmentado (Garcia \& Pirani 2003) e pelo pouco conhecimento de sua dinâmica em resposta às perturbações antrópicas, gerando dúvidas sobre sua origem antrópica ou natural.

De modo geral, a vegetação do PEJ é bastante alterada, fato evidenciado pela abundância de espécies pioneiras, como, por exemplo, aquelas pertencentes aos gêneros Cecropia, Croton e Alchornea, ou também as espécies da família Solanaceae e os subarbustos do gênero Sida, bastante comuns em áreas de estágios iniciais de sucessão. Contudo, ao longo das trilhas percorridas, a vegetação secundária alterna-se com trechos mais bem conservados, onde ocorrem espécies características dessa condição, como Heisteria silvianii Schwacke, Pouteria caimito (Ruiz \& Pav.) Radlk., Sloanea monosperma (Aubl.) Benth. e Tovomitopsis paniculata (Spreng.) Planch \& Triana.

Dentre as espécies amostradas, verificou-se a ocorrência de 14 espécies enquadradas em alguma das categorias de ameaça das listas oficiais de espécies ameaçadas de extinção (Tabela 2), das quais 10 ocorreram na trilha do Mauro, nove na trilha do Pai Zé e cinco na trilha das Garças. Merecem destaque Nectandra debilis Mez (Lauraceae), classificada como "criticamente em perigo" de acordo com a lista mundial e "em perigo" segundo a lista estadual, e Mollinedia oligotricha Perkins (Monimiaceae), incluída na categoria "presumivelmente extinta" no estado. A presença dessas espécies reforça a importância da conservação e proteção de remanescentes florestais, mesmo quando a vegetação é secundária ou quando há fortes pressões antrópicas no local, como enfatizado por Franco et al. (2007).

Ao longo das trilhas foram registradas também 20 espécies exóticas (Tabela 3), das quais oito são nativas do Brasil, porém com ocorrência natural fora do estado de São Paulo (Lorenzi 2002) ou mesmo dentro do estado, mas em formações florestais distintas da encontrada no PEJ. Grande parte dessas espécies foi plantada na década de 40 por determinação do decreto 10877, de 30/12/1939, na ocasião da aquisição da Fazenda Jaraguá pelo governo do estado. Posteriormente, novas espécies foram plantadas espontaneamente por um guarda-parque. Aparentemente, nenhuma dessas espécies está em processo de expansão populacional ou exerce dominância sobre a comunidade, porém apenas estudos específicos poderão avaliar se de fato não há interferência sobre as espécies nativas. Portanto, um programa de monitoramento das populações de espécies exóticas é fundamental para avaliar possíveis alterações na estrutura da comunidade ao longo do tempo e orientar medidas de conservação e manejo.

Tabela 2. Espécies arbustivas e arbóreas registradas no Parque Estadual do Jaraguá, São Paulo - SP e enquadradas em alguma das categorias de ameaça, de acordo com as listas oficiais de espécies ameaçadas no estado de São Paulo (SMA - Mamede et al. 2007), no Brasil (BR - Biodiversitas 2008) e no mundo (IUCN 2006). EX - Presumivelmente extinta; CR - Criticamente em perigo; EN - Em perigo; VU - Vulnerável.

Table 2. Tree and shrub species of the Jaraguá State Park, São Paulo - SP according to their threat categories (EX - Presumably extinct; CR - Critically endangered; EN - Endangered; VU - Vulnerable) defined on the Red list of threatened plant species at São Paulo State (SMA- Mamede et al. 2007); Red list of threatened plant species in Brazil (BR - Biodiversitas 2008); World red list of threatened plant species (IUCN 2006).

\begin{tabular}{|c|c|c|c|c|}
\hline Família & Espécie & SMA & $\mathbf{B R}$ & IUCN \\
\hline \multicolumn{2}{|l|}{ Arecaceae } & VU & EN & \\
\hline & Euterpe edulis Mart. & & & \\
\hline & Handroanthus botelhensis A. H. Gentry & & $\mathrm{EN}$ & \\
\hline \multicolumn{5}{|c|}{ Fabaceae (Caesalpinioideae) } \\
\hline & Senna angulata (Vogel) H. S. Irwin \& Barneby & VU & & \\
\hline & Machaerium villosum Vogel. & & & VU \\
\hline \multicolumn{5}{|l|}{ Lauraceae } \\
\hline & Nectandra debilis $\mathrm{Mez}$ & EN & & $\mathrm{CR}$ \\
\hline \multicolumn{5}{|l|}{ Meliaceae } \\
\hline & Cedrela ssilis Vell. & & & EN \\
\hline \multicolumn{5}{|l|}{ Myrtaceae } \\
\hline & Eugenia prasina $\mathrm{O}$. Berg & & & VU \\
\hline & Gomidesia tijucensis (Kiaersk) D. Legrand & VU & & \\
\hline & Myrceugenia campestris (DC.) D. Legrand \& Kausel & & & VU \\
\hline & Siphoneugenia densiflora O. Berg. & & & VU \\
\hline \multicolumn{5}{|l|}{ Proteaceae } \\
\hline & Euplassa cantareirae Sleumer & VU & & \\
\hline \multicolumn{5}{|l|}{ Rutaceae } \\
\hline & Balfourodendron riedelianum (Engl.) Engl. & & & EN \\
\hline
\end{tabular}


Flora do Parque Estadual do Jaraguá

Tabela 3. Espécies arbustivas e arbóreas exóticas registradas no Parque Estadual do Jaraguá, São Paulo - SP (Ga - trilha das Garças; Ma - trilha do Mauro; PZ - trilha do Pai Zé). (X) Presença; ( ) Ausência. Espécies seguidas por um asterisco (*) indicam que são nativas do Brasil, mas com ocorrência natural fora do estado de São Paulo ou dentro do estado, mas em outras formações, ou ainda com registro de que tenham sido plantadas no Parque.

Table 3. Exotic tree and shrub species found at the Jaraguá State Park, São Paulo - SP (Ga - Garças trail; Ma - Mauro trail; PZ - Pai Zé trail). (X) Presence; ( ) Absence. Scientific names followed by an asterisk (*) indicate brazilian species which occur naturally out of São Paulo state or even inside the State but in other forest formations and with records that they have been planted at the study site.

\begin{tabular}{|c|c|c|c|c|c|}
\hline \multirow[t]{2}{*}{ Família } & \multirow[t]{2}{*}{ Espécie } & \multirow[t]{2}{*}{ Nome Popular } & \multicolumn{3}{|c|}{ Trilhas } \\
\hline & & & Ga & Ma & PZ \\
\hline \multicolumn{6}{|l|}{ Araucariaceae } \\
\hline & Araucaria angustifolia (Bertol.) Kuntze * & araucária & $\mathrm{X}$ & & \\
\hline \multicolumn{6}{|l|}{ Arecaceae } \\
\hline & Arconthophoenix cunninghamii $\mathrm{H}$. Wendl. \& Drude & palmeira-real & & & $\mathrm{X}$ \\
\hline \multicolumn{6}{|l|}{ Euphorbiaceae } \\
\hline & Euphorbia pulcherrima Willd. ex Klotzsch & bico-de-papagaio & & & $\mathrm{X}$ \\
\hline \multicolumn{6}{|c|}{ Fabaceae (Caesalpinioideae) } \\
\hline & Caesalpinia pluviosa DC. * & sibipiruna & & & $\mathrm{X}$ \\
\hline & Peltophorum dubium (Spreng.) Taub *. & canafístula & & & $\mathrm{X}$ \\
\hline & Schizolobium parahyba (Vell.) S. F. Blake * & guapuruvu & $\mathrm{X}$ & $\mathrm{X}$ & $\mathrm{X}$ \\
\hline \multicolumn{6}{|l|}{ Lauraceae } \\
\hline & Persea americana Mill. & abacateiro & $\mathrm{X}$ & $\mathrm{X}$ & $\mathrm{X}$ \\
\hline \multicolumn{6}{|l|}{ Melastomataceae } \\
\hline & Tibouchina granulosa (Desr.) Cogn. * & quaresmeira & & & $\mathrm{X}$ \\
\hline \multicolumn{6}{|l|}{ Meliaceae } \\
\hline & Melia azedarach $\mathrm{L}$. & cinamomo & & $\mathrm{X}$ & \\
\hline \multicolumn{6}{|l|}{ Moraceae } \\
\hline & Artocarpus heterophyllus Lam. & jaca & & & $\mathrm{X}$ \\
\hline & Maclura tinctoria (L.) D. Don ex Steud. * & taiúva & & & $\mathrm{X}$ \\
\hline \multicolumn{6}{|l|}{ Myrtaceae } \\
\hline & Eucalyptus spp. & eucalipto & $\mathrm{X}$ & & $\mathrm{X}$ \\
\hline & Psidium guajava $\mathrm{L}$. & goiabeira & & & $\mathrm{X}$ \\
\hline \multicolumn{6}{|l|}{ Pinaceae } \\
\hline & Pinus eliottii Engelm. & pinus & & & $\mathrm{X}$ \\
\hline \multicolumn{6}{|l|}{ Pittosporaceae } \\
\hline & Pittosporum undulatum Vent. & pau-incenso & & & $\mathrm{X}$ \\
\hline \multicolumn{6}{|l|}{ Rhamnaceae } \\
\hline & Hovenia dulcis Thunb. & uva-japonesa & & $\mathrm{X}$ & \\
\hline \multicolumn{6}{|l|}{ Rosaceae } \\
\hline & Eriobotrya japonica (Thunb.) Lindl. & nespereira & $\mathrm{X}$ & $\mathrm{X}$ & $\mathrm{X}$ \\
\hline \multicolumn{6}{|l|}{ Rubiaceae } \\
\hline & Coffea arabica $\mathrm{L}$. & café & & $\mathrm{X}$ & $\mathrm{X}$ \\
\hline \multicolumn{6}{|l|}{ Rutaceae } \\
\hline & Esenbeckia leiocarpa Engl. * & guarantã & & & $\mathrm{X}$ \\
\hline & Metrodorea stipularis Mart. * & chupa-ferro & & & $\mathrm{X}$ \\
\hline
\end{tabular}

A despeito do grau de conservação da vegetação e das fortes pressões antrópicas a que está submetido, o Parque Estadual do Jaraguá exerce papel importante na conservação da flora arbustivo-arbórea da região metropolitana de São Paulo, sobretudo para a proteção de espécies enquadradas em alguma das categorias de ameaça. A ocorrência de uma fisionomia distinta da floresta ombrófila densa e da floresta estacional semidecidual na porção mais elevada do PEJ deve ser considerada como objeto de estudos futuros, incluindo o resgate do histórico da área por fotografias aéreas, análises geomorfológicas e o levantamento de outras formas de vida para que se possa classificar adequadamente e compreender a dinâmica dessa vegetação. Com isso, será possível avaliar a necessidade do manejo das espécies invasoras e de ações de proteção das espécies nativas, uma vez que se trata de uma área de fácil acesso, com intensa visitação e altamente vulnerável.

\section{Agradecimentos}

Aos funcionários do Parque Estadual do Jaraguá, em especial a Vladimir A. de Almeida, pelo incondicional apoio logístico. À Ângela Borges Martins, Gabriel Dalla Colletta, João Aurélio Pastore, João Batista Baitello, João Renato Stehmann, João Semir, Kikyo Yamamoto, Marcelo Monge Egea, Natália Macedo Ivanauskas e Osny Tadeu Aguiar pelo auxílio nas identificações botânicas. À Isabel Mattos, Marina Kanashiro e Márcio Rossi, pelo auxílio na delimitação da área de campo e confecção do mapa. Ao CNPq, pela bolsa concedida à R. C. Sousa. 


\section{Referências Bibliográficas}

AB'SÁBER, A. 1970a. As "ilhas” de cerrados das bacias de Taubaté, São Paulo e Atibaia. Cad. Cienc. Terr. 6:20-24.

AB'SÁBER, A. 1970b. O mosaico primário de matas e cerrados do Planalto Paulistano. Cad. Cienc. Terr. 6:25-29.

AB'SÁBER, A. 2003. Os domínios de natureza no Brasil: potencialidades paisagísticas. Ateliê Editorial, São Paulo.

BEHLING, H. 1998. Late quaternary vegetational and climatic changes in Brazil. Rev. Palaeobot. Palyno. 99:143-156.

BERNACCI, L.C., FRANCO, G.A.D.C., CATHARINO, E.L.M., DURIGAN, G. \& METZGER, J.P. 2006. O efeito da fragmentação florestal na composição e riqueza de árvores na região da Reserva Morro Grande (Planalto de Ibiúna, SP). Rev. Inst. Flor. 18(1):121-166.

BIODIVERSITAS. Lista oficial de espécies ameaçadas de extinção no Brasil. Disponível em: <http://www.biodiversitas.org.br/florabr/grupo3fim.asp>. (último acesso em 21/05/2008).

CATHARINO, E.L.M., BERNACCI, L.C., FRANCO, G.A.D.C., DURIGAN, G. \& METZGER, J.P. 2006. Aspectos da composição e diversidade dos componentes arbóreo das florestas da Reserva Florestal do Morro Grande, Cotia, SP. Biota Neotrop. 6(2): http://www.biotaneotropica.org.br/v6n2/pt/ abstract?article+bn00306022006 (último acesso em 21/05/2008).

DEAN, W. 1996. A ferro e fogo: a história da devastação da Mata Atlântica brasileira. Companhia das Letras, São Paulo.

DISLICH, R., CERSÓSIMO, L. \& MANTOVANI, W. 2001. Análise da estrutura de fragmentos florestais no Planalto Paulistano - SP. Rev. Bras. Bot. 24(3):321-332.

DURIGAN, G., BAITELLO, J.B., FRANCO, G.A.D.C. \& SIQUEIRA, M.F. 2004. Plantas do Cerrado Paulista: imagens de uma paisagem ameaçada. Páginas \& Letras Editora e Gráfica, São Paulo.

Durigan, G. 2006. Observation on the southern cerrados and their relationships with the core area. In Neotropical savannas and dry forests: diversity, biogeography and conservation (T. Pennington, G.P. Lewis \& J.A. Ratter, orgs.). Taylor \& Francis, London, p. 66-77.

FIDALGO, O. \& BONONI, V.L.R. 1984. Técnicas de coleta, preservação e herborização de material botânico. Instituto de Botânica, São Paulo.

FRANCO, G.A.D.C., SOUZA, F.M., IVANAUSKAS, N.M., MATTOS, I.F.A., BAITELLO, J.B., AGUIAR, O.T., CATARUCII, A.F. \& POLISEL, R.T. 2007. Importância dos remanescentes florestais de Embu (São Paulo) para a conservação da flora regional. Biota Neotrop. 7(3): http://www. biotaneotropica.org.br/v7n3/pt/abstract?article+bn02507032007 (último acesso em 23/10/2008).

GANDOLFI, S., LEITÃO-FILHO, H.F. \& BEZERRA, C.L.F. 1995. Levantamento florístico e caráter sucessional das espécies arbustivoarbóreas de uma Floresta Mesófila Semidecídua no município de Guarulhos, SP. Rev. Bras. Biol. 55(4):753-767.

GARCIA, R.J.F. \& PIRANI, J.R. 2001. Estudo florístico dos componentes arbóreo e arbustivo da mata do Parque Santo Dias, São Paulo, SP, Brasil. Bol. Bot. Univ. 19:15-42.

GARCIA, R.J.F. \& PIRANI, J.R. 2003. Revisão sobre o diagnóstico e caracterização da vegetação campestre junto à crista de serras, no Parque Estadual da Serra do Mar, São Paulo, SP, Brasil. Hoehnea, 30(3):217-242.

GARCIA, R.J.F. \& PIRANI, J.R. 2005. Análise florística, ecológica e fitogeográfica do Núcleo Curucutu, Parque Estadual da Serra do Mar (São Paulo, SP), com ênfase nos campos junto à crista da Serra do Mar. Hoehnea, 32(1):1-48.

Instituto Florestal de São Paulo. Unidades de Conservação: Parque Estadual do Jaraguá. Disponível em: <http://www.iflorestal.sp.gov.br/unidades_ conservacao/index.asp >. (último acesso em 12/03/2007).

International Plant Names Index - IPNI. Disponível em: <http://www.ipni.org/ ipni/plantnamesearchpage.do>. (último acesso em 10/04/2008).

International Union for Conservation of Nature - IUCN. Lista vermelha de espécies ameaçadas de extinção da união internacional para a conservação da natureza. 2006. Disponível em: <http://www.iucnredlist.org>. (último acesso em 21/11/2006).
KÖPPEN, W.P. 1948. Climatologia: con un estudio de los climas de la tierra. Fondo de Cultura Economica, México.

KRONKA, F.J.N., NALON, M.A., MATSUKUMA, C.K., KANASHIRO, M.M., YWANE, M.S.S., PAVÃO, M., LIMA, L.M.P.R., GUILLAUMON, J.R., BAITELLO, J.B. \& BARRADAS, A.M.F. 2005. Inventário florestal da vegetação natural do estado de São Paulo. Secretaria do Meio Ambiente; Instituto Florestal; Imprensa Oficial, São Paulo.

LEITÃO-FILHO, H.F. 1992. A flora arbórea da Serra do Japi. In História Natural da Serra do Japi: ecologia e preservação de uma área no Sudeste do Brasil (L.P.C. Morellato, org.). Editora da UNICAMP, Campinas, p. 40-63.

LONGHI-WAGNER, H.M., BITTRICH, V., WANDERLEY, M.G.L. \& SHEPHERD, G.J. 2001. Flora Fanerogâmica do Estado de São Paulo Poaceae. V. 1. FAPESP-HUCITEC, São Paulo.

LORENZI, H. 2002. Árvores Brasileiras: manual de identificação e cultivo de plantas arbóreas nativas do Brasil. 4 ed. Editora Plantarum Ltda, Nova Odessa.

MAMEDE, M.C.H., SOUZA, V.C., PRADO, J., BARROS, F., WANDERLEY, M.G.L. \& RANDO, J.G. 2007. Livro vermelho das espécies vegetais ameaçadas do Estado de São Paulo. Instituto de Botânica; Imprensa Oficial, São Paulo.

MEIRA NETO, J.A.A., BERNACCI, L.C., GROMBONE, M.T., TAMASHIRO, J.Y. \& LEITÃO-FILHO, H.F. 1989. Composição florística da floresta semidecídua de altitude do Parque Municipal da Grota Funda (Atibaia, Estado de São Paulo). Acta Bot. Bras. 3(2):51-74.

Missouri Botanical Garden - MOBOT. Disponível em: <http://www.tropicos. org/>. (último acesso em 27/12/2008).

OGATA, H. \& GOMES, E.P.C. 2006. Estrutura e composição da vegetação no Parque CEMUCAM, Cotia, SP. Hoehnea, 33(3):371-384.

OLIVEIRA, J.B., CAMARGO, M.N., ROSSI, M. \& CALDERANO FILHO, B. 1999. Mapa pedológico do estado de São Paulo: legenda expandida. 1 ed. Instituto Agronômico; Embrapa Solos, Campinas; Rio de Janeiro.

OLIVEIRA-FILHO, A.T. \& FONTES, M.A.L. 2000. Patterns of floristic differentiation among Atlantic Forests in Southeastern Brazil and the influence of climate. Biotropica, 32(4b):793-810.

RIBEIRO, J.F. \& WALTER, B.M.T. 1998. Fitofisionomias do bioma Cerrado. In Cerrado: ambiente e flora (S.M. Sano \& S.P. Almeida, eds.). EMBRAPACPAC, Planaltina, p. 89-166.

ROQUE, F.O., TRIVINHO-STRIXINO, S., STRIXINO, G., AGOSTINHO, R.C. \& FOGO, J.C. 2003. Benthic macroinvertebrates in streams of the Jaragua State Park (Southeast of Brazil) considering multiple spatial scales. J. Insect Conserv. 7(2):63-72.

Royal Botanic Gardens. Kew World Checklist Series. Disponível em: <http:// apps.kew.org/wcsp/home.do>. (último acesso em 04/11/2008).

SOS Mata Atlântica. Novo dados apontam desmatamento. Disponível em: $<$ http://www.sosma.org.br/index.php?section=content\&action=content Details\&idContent=347>. (último acesso em 29/12/2008).

SOUZA, V.C. \& LORENZI, H. 2007. Botânica Sistemática: guia ilustrado para identificação das famílias de Angiospermas da flora brasileira, baseado em APG II. 2 ed. Instituto Plantarum, Nova Odessa.

USTERI, A. 1908. Relatório da Seção Botânica. Typografia Brazil de Rothschild \& Co., São Paulo. Anuário da Escola Politécnica de São Paulo.

VELOSO, H.P., RANGEL FILHO, A.L.R. \& LIMA J.C.A. 1991. Classificação da vegetação brasileira adaptada a um sistema universal. IBGE, Rio de Janeiro.

VENTURA, A., BERENGUT, G. \& VICTOR, M.A.M. 1965-1966. Características edafo-climáticas das dependências do Serviço Florestal do Estado de São Paulo. Silvic., São Paulo, 4-5(4):57-140.

VICTOR, M. 1975. A devastação florestal. Sociedade Brasileira de Silvicultura, São Paulo.

ZILLER, S.R. 2001. Plantas exóticas invasoras: a ameaça da contaminação biológica. Cienc. Hoje, 30(178):77-79.

Recebido em 06/01/09

Versão reformulada recebida em 31/03/09

Publicado em 01/04/09 